\title{
Urinary Tract Infection Risk Assessment By Non- Thermal Plasma In Iraqis Patients
}

\author{
Mohammed Ubaid Hussein (Ph.D ,Medical Physics )*, Rana Talb Mohsen(Master., Medicine Microbiology) **
}

\section{ABSTRACT}

Background: In the present study used device jet plasma needle with atmospheric pressure which generates non thermal plasma jet to measure treatment potent with plasma against pathogenic bacteria founded in UTI was inactivated with plasma at $10 \mathrm{sec}$,

Objective:. This work included the application of the plasma produced from the system in the field of bacterial sterilization, where sample of Gram- negative bacteria (Escherichia coll) were exposed to intervals (1-10)second . Midstream Urine samples swabs were obtained from patients with urinary tract infections.

Type of the study: Cross -sectional study.

Methods: The work were used in this study obtained from studying 100 urine samples, the age of patients ranged between 10 years to 60 years. They were 60 females and 40 males. These samples were cultured on culture media to isolate bacterial colonies .After that, bacteria were identified by means of highly specific investigations Escherichia coli, plasma needle treatment is applied on bacteria through sterilization, and adhesion.

Results : It was found that the percentage of the killing of Gram-negative bacteria (E.coli) was $100 \%$ at (10) second, also decreasing bacterial adhesion on epithelial cells, where numbers adhesion bacterial with uroepithelial cells decrease after treatment with plasma needle.

Conclusion : From this work, it has been observed that applied voltage ,distance between plasma needle and treatment model as well as time treatment effect on inactivation bacteria and sterilization, also it effect on decreasing bacterial adhesion on epithelial cells, where numbers adhesion bacterial with uroepithelial cells decrease after treatment with plasma needle .

Keywords : Urinary Tract Infection, plasma needle, adhesion ,E. coli bacteria

\section{Al-Kindy College Medical Journal 2017: Vol. 13 No.1} Page: 86-91

*Department of physiology and medical physics, College of Medicine, Anbar University, Anbar, Iraq.

'Department of biochemistry, College of Medicine, Anbar University, Anbar, Iraq.

Received $15^{\text {th }}$ Feb 2017, accepted in final $30^{\text {th }}$ March 2017

Corresponding to Mohammed Ubaid Hussein, email: mmphysics361@gmail.com
U rinary Tract Infection (UTI) is an infection involving the kidneys, ureters, bladder, or urethra. These are the structures that urine passes through before being eliminated from the body.it is an infection that affects part of the urinary tract, kidneys are two bean-shaped organs. They are located in the abdomen on either side of the spine. The kidneys filter blood to remove excess water, salt, potassium, urea and other substances. The waste products are then excreted as urine. ${ }^{[1]}$.

These functions make them important in the regulation of blood pressure. Kidneys are also very sensitive to changes in blood sugar levels and blood pressure and electrolyte balance. Both diabetes and hypertension can cause damage to these organs.

Two ureters, narrow tubes about 10 inches long, drain urine from each kidney into the bladder. The urethra is a small tube connecting the bladder with the outside of the body. A muscle called the urinary sphincter, located at the junction of the bladder and the urethra, must relax at the same time the bladder contracts to expel urine ${ }^{[2]}$.

Any part of this system can become infected. As a rule, the farther up in the urinary tract the infection is located, the more serious it is.

The upper urinary tract is composed of the kidneys and ureters. Infection in the upper urinary tract generally affects the kidneys (pyelonephritis), which can cause fever, chills, nausea, vomiting, and other severe symptoms. When it affects the lower urinary tract it is known as a bladder infection (cystitis) and when it affects the upper urinary tract it is known as kidney infection (pyelonephritis) ${ }^{[1]}$
Symptoms from a lower urinary tract include pain with urination, frequent urination, and feeling the need to urinate despite having an empty bladder ${ }^{[2]}$. Symptoms of a kidney infection include fever and flank pain usually in addition to the symptoms of a lower UTI ${ }^{[3]}$. Rarely the urine may appear bloody ${ }^{[3]}$.In the very old and the very young, symptoms may be non-specific ${ }^{[1,4]}$.

If bacteria move from the infected kidney into the blood. This condition is called sepsis. Sepsis can cause dangerously low blood pressures, shock, and death.

History and physical exam may suggest you have a lower or upper UTI. Definitive diagnosis requires a "clean catch" urine specimen. This is urine collected from the middle of the urinary stream. urine will be cultured for bacteria. This can identify the cause of infection [3]

Escherichia coli (E. coli) is a classic opportunistic pathogen found in hospitals. The World Health Organization professes that this bacterium is one of the primary pathogens of hospital acquired infection. E. coli contributing to a large percentage of nosocomial infections ranks first in the infection rate of various gramnegative nosocomial pathogens. In recent years, because of the multi-drug resistant mechanism of $E$. coli, infection incidents have occurred frequently, and the drug-resistance of the bacterium has gradually risen ${ }^{[5,6]}$ On blood agar, the colonies appeared 3-4 $\mathrm{mm}$ in diameter, on MacConkey agar; the colonies were red, since this organism is a lactose fermenter ${ }^{[6,7]}$.

Plasma is an ionized gas containing free moving charge carriers: electrons and ions ${ }^{[8]}$. Non-thermal atmospheric pressure plasmas are very effective in 
killing bacteria. This makes these plasmas very useful for various biological and medical applications, such as: sterilization of medical instruments, decontamination in biological warfare and air filters in hospitals ${ }^{[9]}$. The plasma needle is a type of non-thermal atmospheric glow discharge, it has a single electrode configuration and is operate by different noble gas (He-Ar), important properties of this type of plasma are that it operate at near room temperature, the plasma does not cause any thermal damage to articles it comes in contact with. This characteristic was open up the possibility to use this plasma for treatment of the heat sensitive materials. Atmospheric pressure discharge plasma is of great interest because of their low costs and simplified operation ${ }^{[10]}$.

Non -equilibrium plasma at atmospheric pressure finds numerous biological and bio-medical applications thanks to their reactive nature .It has been tested on large variety of bacteria ,spores, viruses for their sterilization and interactions of plasma with live tissue ,e.g. skin disinfection ,blood coagulation ,wound healing , density ${ }^{[11,12]}$. In bio-decontamination by plasma, it is crucial to understand the role of various mechanisms involved. The significant mechanisms depend on the plasma composition (gas), temperature, treated microorganisms and the environment (air, water, surfaces, etc. ${ }^{[13]}$.

The most common cause of infection is Escherichia coli, though other bacteria or fungi may rarely be the cause [4]. Kidney infection, if it occurs, usually follows a bladder infection but may also result from a blood-borne infection. ${ }^{[14]}$.

In women, they are the most common form of bacterial infection $^{[15]}$. Up to $10 \%$ of women have a urinary tract infection in a given year and half of women having at least one infection at some point in their lives ${ }^{[2]}$.

The bacteria that cause urinary tract infections typically enter the bladder via the urethra. It is believed that the bacteria are usually transmitted to the urethra from the bowel, with females at greater risk due to their anatomy. After gaining entry to the bladder, $E$. Coliare able to attach to the bladder wall and form a biofilm that resists the body's immune response ${ }^{[2]}$.

Rates of asymptomatic bacteria in the urine increase with age from two to seven percent in women of child bearing age to as high as $50 \%$ in elderly women in care homes ${ }^{[16]}$. Rates of asymptomatic bacteria in the urine among men over 75 are between $7-10 \%$.Asymptomatic bacteria in the urine occurs in $2 \%$ to $10 \%$ of pregnancies $[3,17]$

Effect adhesions on Epithelial cells: Adhesions are cellsurface components or appendages of bacteria that facilitate bacterial adhesion or adherence to other cells or to inanimate surfaces. Adhesions are a type of factor. Adherence is an essential step in bacterial pathogenesis or infection, required for colonizing a new host ${ }^{[18]}$. Most fimbriae of gram-negative bacteria function as adhesions, but in many cases it is a minor subunit protein at the tip of the fimbriae that is the actual adhesin. In gram-positive bacteria, a protein or polysaccharide surface layer serves as the specific adhesin. To effectively achieve adherence to host surfaces, many bacteria produce multiple adherence factors called adhesins ${ }^{[19]}$

Epithelial cells cover the whole surface of the body. It is made up of cells closely packed and ranged in one or more layers. This tissue is specialized to form the covering or lining of all internal and external body surfaces. An epithelial cell that occurs on surfaces on the interior of the body is known as endothelium. Epithelial cells are packed tightly together, with almost no intercellular spaces and only a small amount of intercellular substance. Epithelial cells, regardless of the type, is usually separated from the underlying tissue by a thin sheet of connective tissue; basement membrane. The basement membrane provides structural support for the epithelium and also binds it to neighbouring structures. ${ }^{[20]}$

Urinary tract infections $\mathrm{UTI}_{\mathrm{s}}$ are the most common disease in human ,adhesion process is first step to establish the infection, where bacteria is double after adhesion to arrive of forming colonization, for bacteria appliance process of adhesion and isolated bacterial power in adhesion depends on saturate extent and receivers concentration within epithelial cells, same method ;bacteria which contains adhesion processes such as Fimbria ability on adhesion with bladder cells consequently cystitis, while loses bacteria of structures can not adhesion consequently excretion with urine.

Bacterial adhesins provide species and tissue tropism. Adhesins are expressed by both

pathogenic bacteria and saprophytic bacteria. This prevalence marks them as key microbial virulence factors in addition to a bacterium's ability to produce toxins and resist the immune defenses of the host. Mature Fim $\mathrm{H}$ is displayed on the bacterial surface as a component of the type 1 fimbrial organelle $\left.{ }^{[18,20}\right]$.

The majority of bacterial pathogens exploit specific adhesion to host cells as their main virulence factor. "A large number of bacterial adhesins with individual receptor specificities have been identified." [19]. Many bacterial pathogens are able to express an array of different adhesins. Expression of these adhesins at different phases during infection play the most important role in adhesion based virulence.

\section{Methods}

\section{Experiment setup}

Plasma needle designed with diameter $1 \mathrm{~mm}$ from interior, this needle constitutes cylindrical tube made from glass material with length $100 \mathrm{~mm}$ interior this glass tube, put other cylindrical tube made from iron material with external diameter $2.7 \mathrm{~mm}$,this tube connect to anode from high voltage power supply about $9.6 \mathrm{kV}$ peak to peak, applied power was lasting of electrical discharge which calculated from simultaneous values of voltage and current about 15 watt and applied frequency $33 \mathrm{kHz}$,it through pass argon gas where discharge between electrode and space through needle hole where plasma generation outside from hole, figure (1) shows plasma needle.

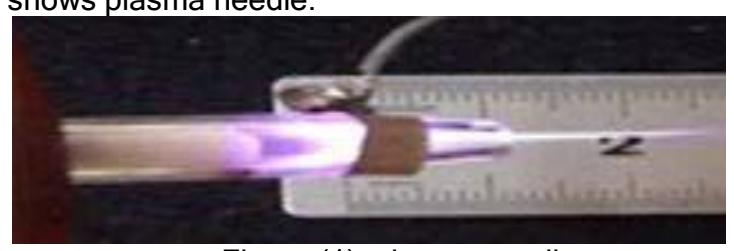

Figure (1): plasma needle

Methods: Hundred patients (100) complaining from different clinical signs and symptoms were admitted to Ramadi Teaching Hospital for seeking medical advise were included in the present study. Midstream urine samples (MSU) were obtained from patient with urinary 
tract infections (UTIs), were examined bacteriological. These samples were collected from patients visiting the out patients urology clinic and patients admitted in the urology department -Ramadi Teaching Hospital.

The results of this work were obtained from studying 100 urine samples. These samples were taken from patients complaining from signs and symptoms of urinary tract infections (UTIs) they were 60 females and 40 males.

The technical detail were described in a methodological study, bacteria were transferred from deep agar subculture where they had kept after isolation to MacConkey agar plates. After growth for 16-48 hrs at 37 ${ }^{0} \mathrm{C}$ in Brain Heart Infusion (BHI) broth, the bacteria were centrifugated and resuspended in Phosphate Buffer Saline (PBS) $\mathrm{pH}$ (7.4). Uroepithelial cells (UECs) were obtained from the sediment of the midstream morning specimen of healthy females without bacteriuria. They were washed and resuspended in PBS ${ }^{[21]} .0 .5 \mathrm{ml}$ of an overnight culture of bacteria in B.H.I broth was gently added to $0.5 \mathrm{ml}$ of UECs suspension. The mixture was mixed by inversion and then was incubated for $1 \mathrm{hr}$ at $37^{\circ} \mathrm{C}$ with shaking every 10 minutes. The UECS were then washed four times with PBS thus unattached bacteria were eliminated by repeated cycle of centrifugation and resuspension ${ }^{[21,22,23]}$. A drop of the final UECS suspension was deposited on a glass slide, air-dried, heat fixed and Gram stained. A control slide with no attached bacteria was stained at the same time. Examination of the slide was done by light microscopy under oil immersion to demonstrate the attachment bacteria to UECs ${ }^{[24,25]}$. Two tubes, one before plasma needle treatment, other after plasma needle treatment.

The adhesion for each bacterial isolate was estimated as the mean number of bacteria adhering to many epithelial cells. The results were compared with the results of control group.

Also ,bacterial samples were grown in brain heart infusion broth at $37^{\circ} \mathrm{c}$ for 20 hour. From this suspension, suspension with a number of bacteria about $10^{8}$ (CFU/ml) were made as determined by $0.5 \mathrm{Mcfarland}$ standard and spectrophotometric assays.

The resuspended culture was serially diluted to $1: 10$, $1: 100,1: 1000,1: 10000$ of the original .The last diluted suspension was used in this experiment to evaluate the effect of plasma needle system on bacteria.

To prevent microbial contamination during experiment, plasma system was placed in a sterile condition. In this experiment $20 \mu \mathrm{L}$ drop of prepared bacterial suspension were placed on agar surface. This volume was selected as it spread to $\approx 1 \mathrm{~cm}^{2}$ over the agar surface ; thus, the area covered by the bacterial sample drop was entirely within the area covered by the insulated plasma needle.

Results : The plasma needle effects, on bacteriology through samples taken of patients, methods sterilization and adhesion were shown. The results of this work were obtained from studying 100 urine samples, the age of patients ranged between 10 years to 60 years. They were 60 females and 40 males, as in figure (2).

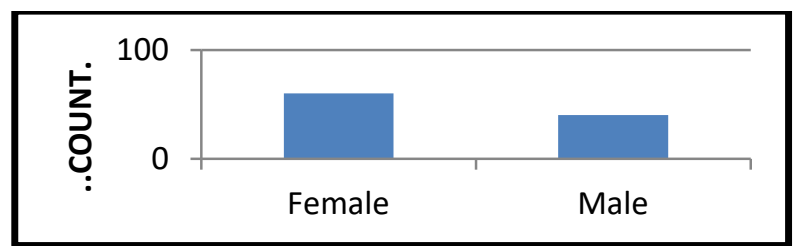

Figure (2): Sex distribution (female \& male) for patterns those help in these experiments.

The glass petri dishes were placed on the ground one by one and exposed to plasma needle for subsequent times (1-20) s.In addition to exposure samples, control samples were inoculated but not exposed to plasma needle . After the treatment, the drop was spread over the entire agar surface and incubated at $37^{\circ} \mathrm{C}$ for $24 \mathrm{~h}$. After incubation, the colony forming units (CFU) were counted in order to check the efficiency of bacterial inactivation using plasma needle system .

1.Treatment of Bacterial Sample:

Escherichia coli were selected to evaluate the inhibitory effect of laboratory- made non-thermal atmospheric pressure plasma (plasma needle) on their growth using brain heart infusion agar culture media, the results shown in figure(3) for Escherichia coli Bactria. The figures shows the reduction in colony forming unit (CFU) as increasing the exposure time as shown figure (4)

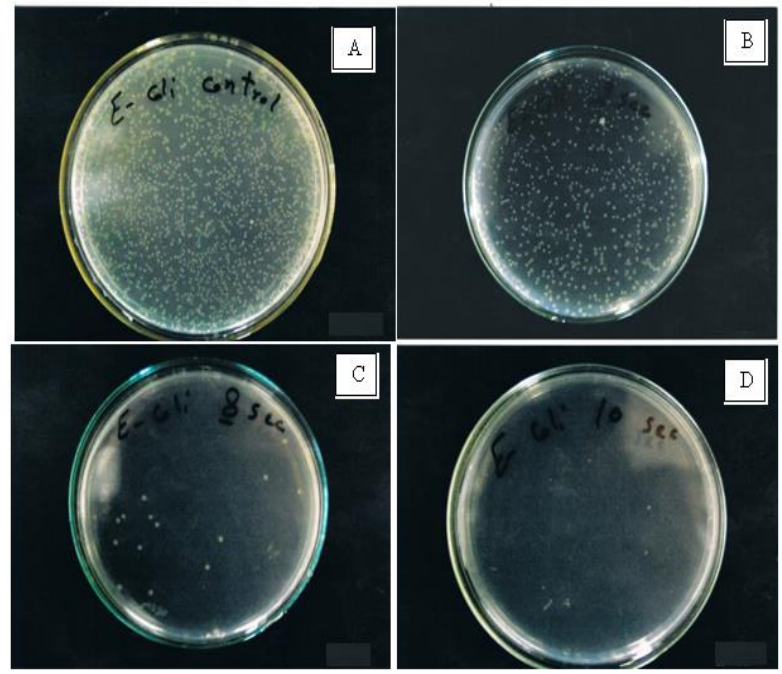

Figure(3): E.coligrowth samples after exposure to plasma needle system

A: control , B: 2 second , C: 8 second , D: 10second

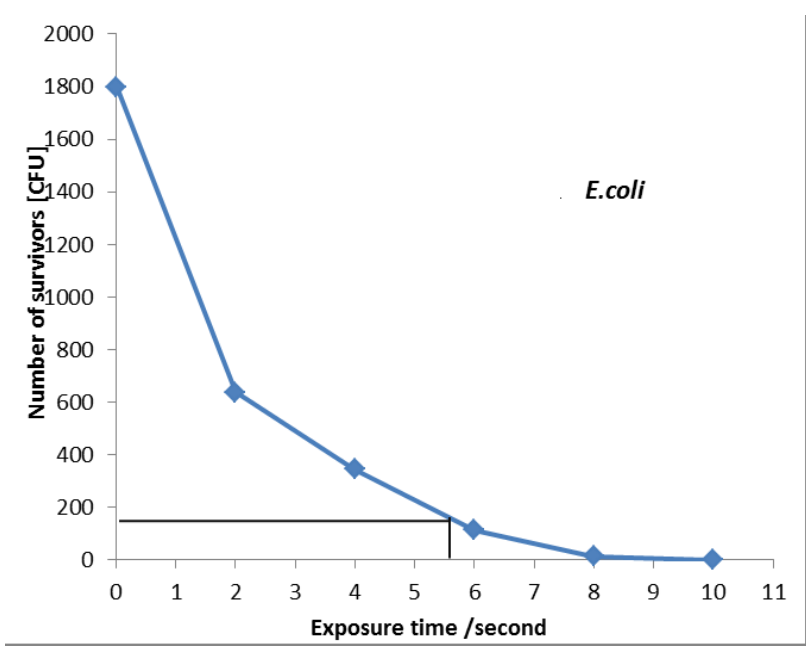

Figure (4):Relation ship between number of survivals (CFU)\& exposure time(sec) of E.Coli bacteria 
The germicidal effect of plasma system on E.coli isolates were analyzed using a germicidal efficiency equation as follows ${ }^{[26]}$.

$$
\text { Germicidal efficiency }=\frac{\left(\mathrm{N}_{\mathrm{o}}-\mathrm{Nt}\right)}{\mathrm{N}_{\mathrm{o}}} \times 100 \%
$$

$\mathrm{N}_{\mathrm{o}}=\mathrm{CFU}$ of non-treated bacteria (control).

$\mathrm{N}_{\mathrm{t}}=$ CFU of treated bacteria.

Results show that plasma needle treatment during 10 seconds effectively sterilized E.coli with a $100 \%$ percentage, as shown figure (5).

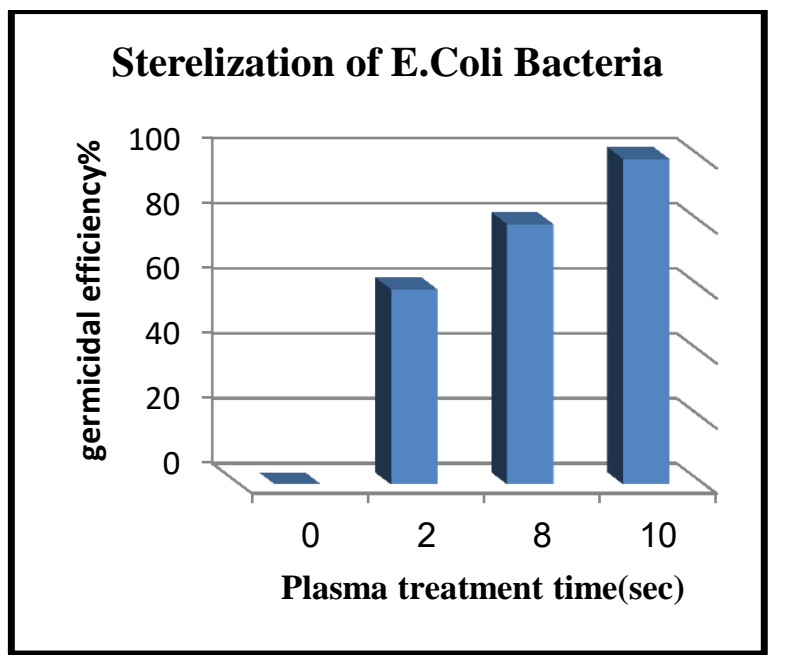

Figure (5): Germicidal efficiency of plasma needle on E.coli at different plasma treatment time.

\section{Adhesion}

This study shows effect the plasma needle on pathogenic bacteria causing $\mathrm{UTI}_{\mathrm{s}}$ and role it in adhesion process of this bacteria on epithelial cells of $\mathrm{UTI}_{\mathrm{s}}$, one type of bacteria was included in this study E.Coli bacteria after isolated from clinical samples of patient suffering $U \mathrm{TI}_{\mathrm{s}}$.

E.Coli bacteria polysaccharides play important role in capability these bacteria on adhesion with epithelial cells, for wallet important affect through first steps of disease these bacteria, where gets contact them and between epithelial cells producing epithelial material, also affect the presence of the wallet in process of building proteins necessary of structure bacterial adhesion.

The adhesion for each bacterial isolate was estimated as the mean number of bacteria adhering to many epithelial cells. E.Coli bacteria was selected to evaluate the inhibitory effect of laboratory -made non -thermal atmospheric pressure plasma(plasma needle) on their growth.The results were compared with the results of control group before treatment by plasma needle .

Figure (6) shows the mean values of No. of bacteria attached to epithelial cells before \& after treatment with plasma, where it decreases after treatment at applied voltage $9.6 \mathrm{kV}$, distances between plasma needle and substance(treatment model) were 2 and $1 \mathrm{~cm}$ and frequency $33 \mathrm{kHz}$ through period $1.30 \mathrm{~min}$.
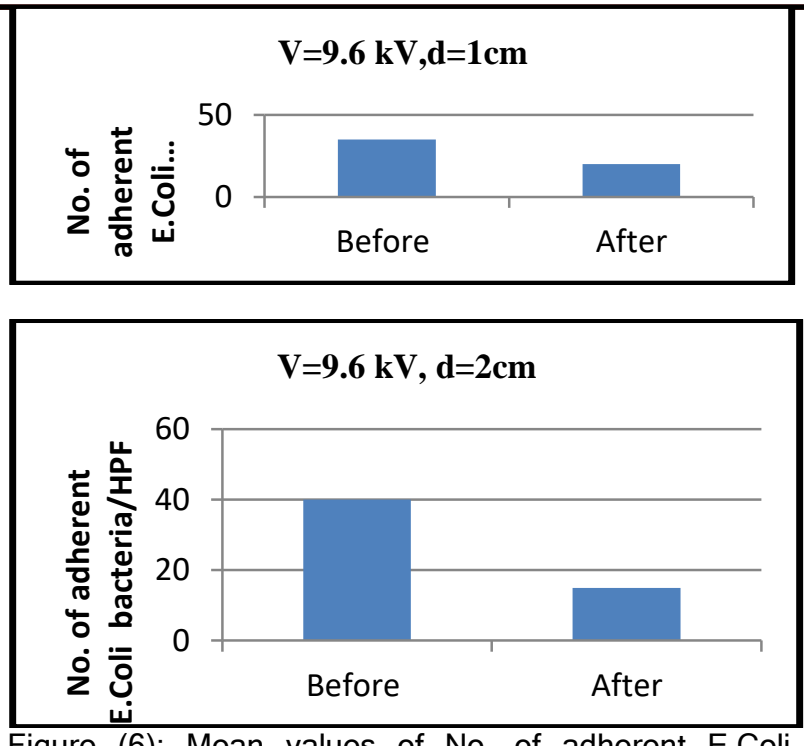

Figure (6): Mean values of No. of adherent E.Coli bacteria to epithelial cells before \& after treatment with plasma needle.

Figure (7) shows the mean values of No. of bacteria attached to epithelial cells before \& after treatment with plasma, where it decreases after treatment at applied voltage $10.6 \mathrm{kV}$, distances between plasma needle and substance(treatment model) were 2 and $1 \mathrm{~cm}$ and frequency $33 \mathrm{kHz}$ through period $1.30 \mathrm{~min}$.

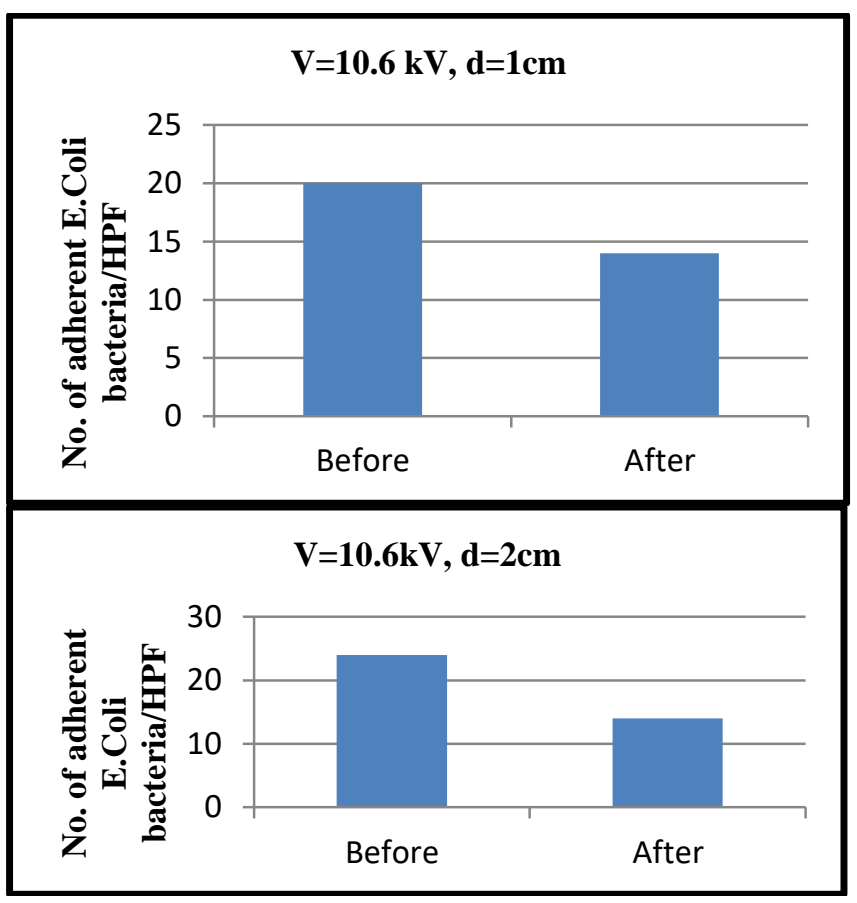

Figure (7): Mean values of No. of adherent E.Coli bacteria to epithelial cells before \& after treatment with plasma needle.

Increasing applied voltage, treatment time and decreasing distances between plasma needle and substance, effect on decreasing No. of bacteria attached to epithelial cells on E.Coli bacteria. 
Discussion: Bacterial adhesion process causes of UTIs through two stages, first recognition phase initial, this stage depends on pili especially Type1-pili and Type $p$ Fimbria with interaction it with epithelial cells and cover it from receptors. Second stage, adhesion more resting where other surface structures involve with it such as Oantigen or lipopolysaccharide founded with outer membrane of Gram negative bacteria where bacteria has this structure led to increasing ability it on adhesion.

Most gram negative bacteria isolated which causes cystitis, fimbria (Type1 Fimbria) ability to connect by mannose units in mucous cells or the cell membranes of host $^{[19,27]}$.

Plasma needle effect in blocking mannose units existing with epithelial cells, thus reduces the bacterial adhesion rate with epithelial cells. As for E.Coli bacteria , cell wall contains Teichoic acid helps adhesion ${ }^{[7]}$, where role of plasma on decreasing adhesin with epithelial cells isolated from $\mathrm{UTI}_{\mathrm{s}}$, consequently these results show that plasma refuses bacteria from adhesion with bladder wall, consequently inactivation process adhesion of bacteria with epithelial cells of UTI.

The specific mechanism for the plasma effect on epithelial cells is similarly unclear. Cold plasma produces long living $\left(\mathrm{O}_{3}, \mathrm{NO}, \mathrm{HO}_{2}, \mathrm{H}_{2} \mathrm{O}_{2}\right)$ and short lived $(\mathrm{OH}, \mathrm{O}$ electronically excited) neutral particles and charged particles(ions and electrons ).All of these could be toxic to cells ,induce low levels of cell membrane damage and potentially change intercellular signaling pathways .Specific plasmas can be created to produce either neutrals or charged particles in order to elucidate the critical mechanism. Charged particles can play a very significant role in the rupture of the outer membrane of bacterial cells.

Conclusions : There was laboratory plasma needle system showed germicidal effect on Gram-negative bacteria(E.Col/). charged particles found in plasma can play a very significant role in the rupture of the outer membrane of bacterial cells, also change of applied voltage and distance by sterilization method, as shown. plasma needle treatment is applied on bacteria through sterilization, and adhesion .From this work it has been observed that applied voltage ,distance between plasma needle and treatment model as well as time treatment effect on inactivation bacteria and sterilization, also it effect on decreasing bacterial adhesion on epithelial cells, where numbers adhesion bacterial with uroepithelial cells decrease after treatment with plasma needle .

Acknowledgments: I would like to express special words of thanks with deepest appreciation of college medicine and Clinical Laboratories in Al-Ramadi General Hospital, also the Staff working in these Laboratories.

\section{References}

[1]Lane, DR; Takhar, SS (August 2011). "Diagnosis and management of urinary tract infection and pyelonephritis.". Emergency medicine clinics of North America. 29 (3): 539-52.

[2]Salvatore S, Salvatore S, Cattoni E, Siesto G, Serati M, Sorice P, Torella M (June 2011). "Urinary tract infections in women.". European journal of obstetrics, gynecology, and reproductive biology. 156 (2): 131-6.
[3]Woodford, HJ; George, J (February 2011). "Diagnosis and management of urinary infections in older people". Clinical Medicine. London. 11 (1): 80-3.

[4] Flores-Mireles, AL; Walker, JN; Caparon, M; Hultgren, SJ (May 2015). "Urinary tract infections: epidemiology, mechanisms of infection and treatment options.". Nature reviews. Microbiology. 13 (5): 269-84.

[5] Philippon A, Arlet G, Jacoby G A., Antimicro-bial Agents and Chemotherapy,Vol.46 :No. 1, 2002.

[6] Turk, D. C. and Porter, I. A. "A short textbook of medical microbiology",.3rd edition, Unibooks English Universities press .p. 115, 1975

[7] Jawetz, E., Melnick, J.L., Adelberg, E. A. Review of medical microbiology. 24th ed.Cha.16, Enterobacteriaceae, Prentice-Hall international. 2007.

[8] X. Li and P. Jia ; Physics of Plasma ; Vol.17,No. 093504, pp. 1-5, 2010.

[9] A . Bogaests, E. Neyts R. Gijbels, and J.V. Mullen; Spectrochimic Acta Part B. Vol. 57, pp. 609 - 658 , 2002.

[10] S. D. Anghel, and A. Simon; Rom. Journ. Phys; 55m, Vol. 1-2 , pp.185 - 193, 2010.

[11] Z. Machala .L. Chladevova M. Pelach ,"Biocidal agents in bio-decontamination by DC discharges in atmospheric air",12th Int Symp High Pres Low Temp Plasma Chem HAKONE XII, Terncianske Teplice, Slovakia, September.Vol. 12-17, pp. 538, 2010.

[12] P. Lukes, M. Clupek,V. Babicky, "Bacterial inactivation by pulsed corona discharge in water, IEEE Pulsed Power Conference, pp. 320, 2009.

[13] Z. Machala,. L. Chladevova, M. Pelach. J. Phys. D Appl. Phys. Vol. 43, pp. 222001, 2010.

[14] Nicolle LE (2008). "Uncomplicated urinary tract infection in adults including uncomplicated pyelonephritis". Urol Clin North Am. 35 (1): 1-12, v. 18061019

[15] Colgan, R; Williams, M (2011-10-01). "Diagnosis and treatment of acute uncomplicated cystitis.". American family physician. 84 (7): 771-6.

[16] Dielubanza, EJ; Schaeffer, AJ (January 2011). "Urinary tract infections in women.". The Medical clinics of North America. 95 (1): 27-41.

[17] Smaill, F.; Vazquez, JC. (2007). "Antibiotics for asymptomatic bacteriuria in pregnancy.". Cochrane Database Syst Rev (2): CD000490.

[18] Boland, T., R. A. Latour, and F. J. Sutzenberger "Molecular basis of bacterial adhesion", 1st ed. Humana Press, Totowa, N.J., p. 29-41, 2000.

[19] Peter Pieroni, Elizabeth A., Worbec, Paranchych, W., and Glen D.Armstrong "Identification of a human erythrocyte receptor for colonization factor antigen I pili expressed by $\mathrm{H} 10407$ Enterotoxigenic E.coli"

.J.Infect.and Immun.Vol.56. No.5 Page 1334-1339, 1988

[20] Eden, C.S., Engberg, I., Hedges, S., Jann, K., VanKooten CConsequences of bacterial attachment in the urinary tract. Bioch. Society. Trans. 17(3); 464-466, 1989.

[21] Ritam Gander and Thomas, V.L. "Distribution type-1 and pili on uropathogenic E.coll'. J. Infec. and Immun.Vol.55 No.2 page 293-297, 1987.

[22]Lomberg H., Cedergren B., Loffler H., Nilsson B., Carlstrom AS., and Eden C. "Influence of blood group on the availability of receptors for attachment of uropathogenic E.coll". Inf. Immun. Mar., Vol.52, Page 919-926., 1986. 
[23] Sato H., and Okinaga. "Role of pili in pathogenesis of Ps. aeruginosa burn infection". Microbiol .Immunol.32:131-139, 1987.

[24] Parkkinen J., Garry N., Rogers, Korhonen T., Dahr W., and Finne J. "Identification of the O-liked sialyoligosccharise of glycophoran $\mathrm{A}$ as the erythrocytes receptors for the S-fimbriated E.coll'. J.Infect. and Immun.vol.54.No.1 Page 37-42. 1986.
[25] Fridman G., Gutsol A., Shekhter A. B., Vasilets V. N., and Fridman A., "Applied plasma medicine," Plasma Processes Polym. 5, 503, 2008.

[26] Miao H. and Yun G. 2011. The Sterilization of Escherichia coli by Dielectric-Barrier Discharge Plasma at Atmospheric Pressure. Applied Surface Sience ,257, pp:7065-7070.

[27] Asscher A.W.,"The challenge of urinary tract infections", Academics press Inc. (London) Ltd, 1-6 and 45-73., 1980. 